\title{
Correspondência intelectual: uma nova perspectiva sobre Furtado
}

[ Intellectual correspondence: a new perspective about Furtado

\section{Mauricio C. Coutinho ${ }^{\mathrm{I}}$}

Celso Furtado: correspondência intelectual - I949-2004. Seleção, introdução e notas: Rosa Freire d’Aguiar. Posfácio: Luiz Felipe de Alencastro. São Paulo: Companhia das Letras, 202 I.

RESUMO - Um comentário sobre a correspondência intelectual de Furtado do período I949-2004. Furtado correspondeu-se com acadêmicos, políticos e personalidades mundiais. A obra apresenta as cartas de Furtado e de seus interlocutores, e esclarece diversos aspectos da vida política e econômica do período. P PALAVRAS-CHAVE - Furtado, correspondência. · ABSTRACT · A comment on the intellectual correspondence of Furtado, in the period I949-2004. Furtado exchanged letters with academics, politicians and word personages. The book presents us the letters from Furtado and from his correspondents, and sheds new lights on several aspects of the political and economic life of the period. - KEYWORDS . Furtado, correspondence.

Recebido em 20 de junho de $202 I$ Aprovado em 30 de junho de $202 I$

COUTINHO, Mauricio C. Correspondência intelectual: uma nova perspectiva sobre Furtado. Revista do Instituto de Estudos Brasileiros, Brasil, n. 79, p. I80-I85, ago. 202I.

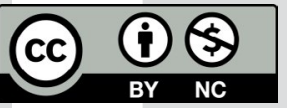

DOI: https://doi.org/Io.II606/issn.23I6-90IX.vIi79pI80-I85

I Universidade Estadual de Campinas (Unicamp, Campinas, SP, Brasil). 
Celso Furtado - correspondência intelectual - I949-2004, organizado por Rosa Freire d'Aguiar e lançado este ano (202I) após intenso trabalho de seleção e edição nos volumosos arquivos de correspondência de Celso Furtado, será recebido como um material valioso pelos estudiosos de sua obra, assim como pelos interessados em história do Brasil e em "desenvolvimentismo" do período do pós-guerra. O volume de certo modo complementa os Diários intermitentes: I937-2002 (FURTADO, 20I9) - o caderno de anotações pessoais de Furtado lançado em 20I9 - e acrescenta outros ângulos de análise a sua trajetória intelectual e política, após os densos volumes da Obra autobiográfica (FURTADO, 20I4).

O que antes de mais nada chama a atenção do leitor - a mim, impressionou - é a qualidade da escrita. Já sabíamos, pelos artigos e livros publicados ao longo de sua vida, que Furtado é um bom escritor. Foge à regra dos economistas e cientistas sociais brasileiros, pois escreve muito bem! No entanto, podia-se esperar que o apuro na redação fosse dirigido às obras editadas, revisadas e postas a circular pelo próprio Furtado. Agora se vê que a suposição não é correta: a correspondência revela a mesma excelência e o mesmo talento literário dos textos editados. Se é verdade que correspondência era a norma de comunicação em sua época, não menos verdade é que as cartas agora divulgadas mostram um apuro na escrita que - digo eu - situa Furtado como um corpo estranho à Academia Brasileira de Letras. Definitivamente, um grande escritor.

Alguns aspectos da correspondência intelectual merecem destaque. Em primeiro lugar, a variedade de missivistas, incluindo um bom número de personalidades mundiais. Vê-se pelos interlocutores que Furtado foi acionado com estima e reverência não apenas pelos colegas da Comissão Econômica para a América Latina (Cepal), por acadêmicos e por um grande conjunto de companheiros de viagem na política brasileira, como por um sem-número de escritores e de personagens da cena mundial, como Ernesto Sábato, Bertrand Russel, Fidel Castro, Henry Kissinger, Jack Lang, Pérez de Cuellar, Robert Kennedy...

Se somarmos a essa lista os intelectuais brasileiros e internacionais que se dirigiam a Furtado por razões específicas, como o comentário a alguma ideia ou trabalho, manifestação de solidariedade ao proscrito político no pós-I964, convites para palestras ou para temporadas em instituições diversas, o panorama causará 
impacto. Furtado se correspondeu com Albert Hirschman, Nicholas Kaldor, Wassily Leontief, Werner Baer, Richard Kahn, Oskar Lange, Luigi Spaventa... Em suma, com intelectuais e economistas de destaque da segunda metade do século XX. Para não falarmos, naturalmente, de correspondentes brasileiros mais ou menos frequentes, como Fernando Henrique Cardoso, Francisco Weffort, Francisco de Oliveira, Maria da Conceição Tavares, Plinio de Arruda Sampaio, Otto Maria Carpeaux, Octavio Ianni, Luciano Martins, Helio Jaguaribe, Francisco Iglesias, Antonio Candido, Florestan Fernandes...

Impossível deixar de solidificar a ideia de que, tanto do ponto de vista das obras produzidas como do reconhecimento intelectual em diversos cantos do mundo, Furtado foi um nome ímpar. Possivelmente, o maior intelectual brasileiro de sua época, e não sob o ponto de vista de qualquer (e indevida) pugna pelo título de “intelectual preferido", senão pelo critério de absorção de atenção. Percebe-se que Furtado foi uma espécie de ponto de referência na vida intelectual brasileira de seu período, a despeito de o maior volume da correspondência abranger a longa temporada na França e no exterior. A par disso, fica claro, em particular pela correspondência do período I964-I975, que diversas elaborações intelectuais do período, envolvendo tópicos como desenvolvimento econômico, estagnação e recuperação, estrutura social, dependência e inserção internacional do Brasil, tiveram Furtado como interlocutor ou formulador decisivo. A esse respeito, as reuniões em Santiago no imediato abril de I964, a correspondência do "clube Bianchi”, o período em Yale e na primeira década de sua temporada francesa - experiências tornadas bem mais claras pela correspondência - situam Furtado como um ponto de referência, e também de propulsão, dos debates sobre o desenvolvimento latino-americano que vieram a se estabelecer no período de disseminação das ditaduras militares.

Um segundo aspecto do volume a destacar é a luz lançada sobre a política brasileira no imediato pós-I964. Como já se sabia - veja-se a Obra autobiográfica -, Furtado nunca foi ingênuo em relação à natureza do regime militar e a suas possibilidades de longa sobrevivência. Acreditou que os militares tinham vindo para ficar, e que a articulação específica entre os militares, a velha política conservadora, os interesses empresariais, a ideologia de uma classe média em ascensão poderia garantir vida longa ao regime ou, ao menos, dar espaço a mudanças apenas secundárias e incapazes de abrandar o autoritarismo e a exclusão social brasileiros.

Pode-se pensar que o ceticismo e a razoável amargura de Furtado teriam sido impulsionados pela perseguição maldosa que lhe foi assegurada pelo regime: dificuldades com passaportes e com vistos, bloqueio a contatos internacionais e mesmo a atividades profissionais, para não falarmos na cassação imediata e na

2 De acordo com Rosa Freire d'Aguiar (2020, p. 382), a correspondência do "clube Bianchi" se iniciou em I965, quando, durante um grande colóquio realizado em Londres "sobre os obstáculos políticos da América Latina”, Celso Furtado, Fernando Henrique Cardoso, Helio Jaguaribe, Aníbal Pinto, Orlando Fals Borda, Jacques Chonchol, percebendo que estavam estudando temas semelhantes, "mas cada um em seu canto [...], resolvem formar o que, hoje, seria um grupo no google, ou até no whatsapp: uma pequena rede de troca de mensagens. O nome Bianchi era o da pizzaria em Londres onde nasceu o clube. Combinam de se escrever mensalmente contando o que cada um está fazendo e comentando o trabalho dos outros”. 
demissão do serviço público - episódios, aliás, bem esclarecidos na correspondência. Longe disso. Na verdade, o panorama que se obtém é o de um Furtado já bastante escaldado por sua experiência com a elite conservadora nordestina, na Superintendência do Desenvolvimento do Nordeste (Sudene), e totalmente alerta aos projetos da direita política brasileira, vocalizados por Lacerda (aliás, um de seus correspondentes). Por outro lado, cético em relação à orientação dos trabalhistas e de João Goulart em particular, assim como absolutamente destoante da visão e das opções da esquerda brasileira, seja no pré-I964, seja no período que transcorre de 1964 ao início dos anos I970. Se somarmos a isso a visão de prazo mais longo do intelectual sobre a natureza do processo de acumulação no pós-guerra e sobre o peso da exclusão social, teremos a base para um pessimismo consistente, o qual, naturalmente, não eliminava a expectativa de (e a luta por) uma transformação política que ensejasse um processo de absorção paulatina da população marginalizada à vida social decente. Na correspondência trocada com Darcy Ribeiro, uma carta de Furtado de 3 de abril de I970 é bastante reveladora: "Você deve recordar-se de nosso encontro em I964, em Santiago, de minha visão 'pessimista' com relação à evolução a médio prazo no Brasil. Hoje, olhando as coisas com mais distância, o que me surpreende é que tenhamos tido vinte anos de relativa liberdade" (p. 68-69). Em diversas outras cartas o tom é o mesmo.

O interessante é que, não obstante um quadro que não dava margem a qualquer otimismo, diversos correspondentes alimentaram a expectativa de um "afrouxamento" do regime, seja ainda no governo Castelo Branco, seja na transição a Costa e Silva. Enfim, até o Ato Institucional n. 5 (AI-5), ou próximo a ele, havia oposicionistas esperançosos de alguma liberalização. Furtado ouvia (lia) seus interlocutores com curiosidade, sem alimentar ilusões. A correspondência é bastante ilustrativa do ânimo oscilante da oposição brasileira, a qual absorvia golpes e, paradoxalmente, alternava indignação com esperança infundada.

Naturalmente, um dos pontos altos do volume é a correspondência com os economistas, seja no período na Cepal, seja no exílio. Essa correspondência é tanto esclarecedora de diversos aspectos do pensamento dos interlocutores e de Furtado, como de sua atuação em posições estratégicas (Banco Nacional de Desenvolvimento Econômico - BNDE, Sudene, Ministério do Planejamento). A volumosa correspondência com Prebisch, por exemplo, testemunha a evolução do pensamento econômico do mestre argentino. A correspondência com Kaldor, Hirschman, Gunder Frank, Ignacy Sachs, Aníbal Pinto, Sunkel, Conceição Tavares, Noyola Vázquez, Regino Boti permite que se obtenha um verdadeiro retrato do pensamento econômico de Furtado a cada momento, envolvendo concepções gerais e mesmo detalhes analíticos. A correspondência trocada com Joseph Love fornece um testemunho sintético do próprio Furtado sobre aspectos de sua obra e de sua contribuição à Cepal. Na carta de 22 de fevereiro de I955 a Noyola Vázquez, Furtado se refere elogiosamente ao trabalho de Lewis sobre desenvolvimento com oferta ilimitada de mão de obra e confirma que na Cepal a mesma perspectiva havia sido adotada. Em correspondência com diversos interlocutores, Furtado reitera que Formação econômica do Brasil (I959), assim como trabalhos anteriores a respeito da evolução da economia brasileira, eram por ele entendidos como contribuições 
ao estudo do "desenvolvimento econômico". Vale dizer, obras que se tornaram referência em história econômica são vistas pelo autor como contribuições ao estudo do "desenvolvimento econômico". Por outro lado, a correspondência com diversos economistas mostra a preocupação com crédito e inflação ainda na década de I950. Se isso não representa surpresa para leitores criteriosos de Formação econômica do Brasil e de outras obras da época, desmente qualquer crítica descuidada a uma suposta pouca consideração dos desenvolvimentistas (e cepalinos) às questões relacionadas a financiamento e inflação.

A correspondência é ainda reveladora de alguns aspectos da abertura política afinal lograda em I985. Sabe-se que Furtado participou ativamente, e com expectativas positivas, das articulações oposicionistas que se desenvolveram com ênfase na segunda metade do governo Figueiredo, chegando mesmo a filiar-se ao Movimento Democrático Brasileiro (MDB). O desfecho é também conhecido: Sarney assume a presidência com a morte de Tancredo, Furtado é encaminhado a missões internacionais na Comunidade Europeia, vindo posteriormente a assumir o Ministério da Cultura. Antes de assumir o Ministério, Furtado já havia escrito sobre cultura e chegara mesmo a transformar-se em um interlocutor reconhecido na área. No Ministério, consolidou sua posição de referência intelectual e política sobre cultura, estimulando o debate e mesmo lançando iniciativas decisivas em uma esfera anteriormente à míngua de interesse político e governamental.

A despeito de a correspondência com personagens da temporada pós-I985, ou pós-anistia, não ser numerosa - vale lembrar que a presença mais constante e afinal a mudança ao Brasil reduziram os contatos epistolares -, há algumas peças deliciosas, como a correspondência com Francisco Iglesias. No entanto, poucos testemunhos há da decidida atuação de Furtado no MDB e nas negociações para a transição Tancredo-Sarney, assim como da razoavelmente inesperada (aos observadores externos) designação a um posto no exterior e mesmo, posteriormente, ao Ministério da Cultura. A esse respeito, pode-se dizer que tanto a Obra autobiográfica como os próprios Diários são bem mais elucidativos. Sabemos que Furtado participou ativamente das discussões internas ao MDB sobre as políticas a serem adotadas diante de uma situação econômica já encaminhada para o desastre, assim como sabemos que, ainda com Tancredo vivo, ele foi praticamente excluído do núcleo das decisões em política econômica. Em resumo, as alternativas propostas (e defendidas em público) por Furtado mostraram-se impalatáveis para a composição política conservadora que acabou por caracterizar a saída do regime militar. Mas isso, como foi dito, transparece muito pouco na correspondência. Ainda assim, algumas cartas do período pós-I975 ou pós-anistia mostram o progressivo engajamento de Furtado na discussão de alternativas ao regime militar, seja na esfera política, seja, em especial, no que se refere às perspectivas de inserção do Brasil em uma ordem econômica internacional muito modificada em relação à do período anterior a I960. A experiência internacional e a abertura aos ares do mundo proporcionaram a Furtado uma percepção das transformações da economia mundial pouco usual em um país cujos intelectuais são em geral autocongratulatórios e pouco abertos ao cosmopolitismo.

Correspondência intelectual nos brinda ainda com um prefácio e um posfácio 
valiosos, escritos respectivamente por Rosa Freire d'Aguiar e Luiz Felipe de Alencastro. Como Rosa Freire d'Aguiar observa na "Introdução", os volumes de correspondência comporão o acervo geral de Furtado, incorporado ao Instituto de Estudos Brasileiros da Universidade de São Paulo (IEB/USP), em processo de organização para acesso do público em geral e de pesquisadores. É notório que nos estudos e pesquisas sobre Furtado realizados nos últimos dez anos, pouca atenção foi dada ao período I965-I980, ressalvados os trabalhos de Renata Bianconi (2014). A correspondência agora publicada, especialmente referida a esse período, representa uma amostra tentadora do que se poderá obter com estudos mais aprofundados da atuação de Celso Furtado à época.

\section{SOBRE O AUTOR}

MAURICIO C. COUTINHO é professor titular do Instituto de Economia da Universidade Estadual de Campinas (Unicamp). coutinho@unicamp.br https://orcid.org/0000-0002-I253-8567

\section{REFERÊNCIAS}

BIANCONI, Renata. L'oeuvre de Celso Furtado à Paris: le parcours d'un intellectuel et homme d'Etat. Thèse de doctorat en Histoire moderne et contemporaine. Sorbonne Université, 20I4.

D’AGUIAR, Rosa Freire. Entrevista concedida a Antônio Corrêa de Lacerda, Carlos Medeiros, Carmem Feijó e Tânia Bacelar. Cadernos do Desenvolvimento - Centenário de Celso Furtado, v. I5, n. 25, jan.-jun. 2020, p. 366-386. Disponível em: http://www.cadernosdodesenvolvimento.org.br/ojs-2.4.8/index.php/ cdes/article/viewFile/505/pdf. Acesso em: 20 maio 202I.

FURTADO, Celso. Formação econômica do Brasil. Rio de Janeiro: Fundo de Cultura, I959.

FURTADO, Celso. Obra autobiográfica. Edição definitiva. Coordenação de Rosa Freire d'Aguiar. São Paulo: Companhia das Letras, 20I4.

FURTADO, Celso. Diários intermitentes: 1937-2002. Organização, apresentação e notas de Rosa Freire d’Aguiar. Prefácio de João Antonio de Paula. São Paulo: Companhia das Letras, 2019. 